\title{
The role of architectural research centers in addressing climate change
}

\author{
John Carmody \\ University of Minnesota, Minneapolis, Minnesota
}

\begin{abstract}
It is clear that an urgent, major transformation needs to happen in the design of the built environment to respond to impending climate change and other environmental degradation. This paper will explain the potential role of architectural research centers in this transformation and provide examples from the Center for Sustainable Building Research (CSBR) at the University of Minnesota. A research center can become a regional hub to coordinate and disseminate critical information. CSBR is leading the establishment of Architecture 2030 standards in Minnesota, assisting local governments in writing green building policy, providing design assistance to local government, developing tools to assist design decision making, providing technical assistance to the affordable housing community in Minnesota, and establishing a regional case study database that includes actual performance information. CSBR is creating a publicly accessible, credible knowledge base on new approaches, technologies and actual performance outcomes. Research centers such as CSBR can be a critical component of the necessary feedback loop often lacking in the building industry. A research center can also fill major gaps in providing in depth professional education as well as be a catalyst for demonstration projects and public education.
\end{abstract}

Conference theme: Green and sustainable architecture

Keywords: sustainable architecture, architectural research center

\section{INTRODUCTION}

Sustainable design today draws from many roots that date back to the energy and environmental concerns of the 1970s but is based on a more holistic and comprehensive vision. There is now recognition that sustainability is not just about the environment and natural resources, it represents a balance between environment, economics and equity. During the 1990s, the impact of the built environment on people and the natural environment became more evident and widely discussed in the design professions. The movement toward more ecological design principles is based on the growing understanding that conventional development practices are not sustainable. According to the Millennium Ecosystem Assessment, "Over the last 50 years, humans have changed ecosystems more rapidly and extensively than in any comparable period of time in human history, largely to meet rapidly growing demands for food, fresh water, timber, fiber, and fuel. This has resulted in a substantial and largely irreversible loss in the diversity of life on Earth" (MEA, 2005). The worldwide impacts of climate change in particular have recently been documented in reports by the United Nations Intergovernmental Panel on Climate Change (IPCC). According to the IPCC Synthesis report, "Warming of the climate system is unequivocal, as is now evident from observations of increases in global average air and ocean temperatures, widespread melting of snow and ice, and rising global average sea level" (IPCC, 2007).

According to the Architecture 2030 initiative, the built environment is responsible for $48 \%$ of carbon $\left(\mathrm{CO}_{2}\right)$ emissions in the United States. The transportation sector is responsible for another $27 \%$ of carbon emissions. Recently, the American Institute of Architects endorsed the goals of Architecture 2030, which sets a target of zero carbon emissions from buildings by 2030 and requires emissions to be reduced by $60 \%$ by 2010 (Architecture 2030, 2007). It is well documented that the building sector uses large shares of the world's wood, minerals, water, and energy and generates a large portion of the waste going to landfills (Worldwatch, 1995).

Planning and design of the built environment not only results in environmental impacts from buildings themselves, but also impacts from the transportation patterns that are established by development. For example, according to a recent Caltrans study, transitoriented development can reduce rates of greenhouse gas emissions by 2.5 to 3.7 tons per year for each household (CALTRANS, 2002).

It is clear that an urgent, major transformation needs to happen in the design of the built environment to respond to impending climate change and other environmental degradation. While there are many 
programs, emerging technologies, and motivated individuals in the design and construction community, there is a danger that systemic change will not occur quickly enough. There is a lack of feedback on what actually works in the field that could inform designers as well as establish the future research agenda. Perhaps most importantly, there are gaps in knowledge and missed opportunities in the fragmented building delivery process. Educational institutions are not able to respond quickly to driving forces for change in society and the profession, while research is not always effectively communicated to practice or education.

While rating systems like LEED have been successful vehicles in raising awareness in the marketplace, they are still not in widespread use. Unless sustainable design is required by a client, there is no urgency to change practice in many firms. Policy changes and code requirements that would drive change occur too slowly. There are many good intentions but the overall picture is one of disconnected parts that do not add up to a whole.

The biggest challenge for research, practice and education is that the magnitude of the problems and need for rapid response is unprecedented. Some scientists indicate that significant reductions in greenhouse gas emissions must occur in the next ten years to avoid catastrophic consequences. Knowledge is expanding quickly but it is not synthesized into forms that enable effective decision making. Current practices may not lead to the desired outcomes and it will be too late. It is well known that feedback loops in the design and construction industry are not well developed. Everyone needs better information now- designers, educators, clients, contractors, manufacturers, state and local governments.

\section{CURRENT STATUS OF SUSTAINABLE GUIDELINES AND RATING SYSTEMS}

Environmental assessment systems, ratings systems, and guidelines have played an important role in raising public awareness and transforming the market for more sustainable building practices in the United States. These systems define criteria for sustainable building and may be used as the basis for establishing requirements or incentives. Voluntary, market-based guidelines may be viewed as a precursor to more formal changes to standards and codes.

The introduction of new assessment and rating systems and the continuous updating of existing ones represent an evolution driven by several factors. These include the expansion of guidelines into new scales of development, additional phases of the process, and customized versions for specific building types. The evolution of guidelines is also driven by the desire for regional variation as well as accommodating new knowledge developed about best methods and practices. A key question in the development and use of these systems is whether they lead to the desired environmental outcomes when applied to real projects. Meeting certain requirements during design does not always translate into predicted performance. Most guidelines consist of a mixture of recommended processes, best practices, and some performance outcomes. Processes and practices are not always measurable and cannot be translated into quantifiable environmental outcomes.

One of the most common ways of assessing sustainable design is the use of point-based ratings systems. Relatively easy to understand and use, the points serve as surrogate indicators of real performance. This does not lead to a rigorous assessment or results that can be compared across projects (Cole, 2006). The drawback is that point-based systems can simply become like a set of specified requirements without fundamentally influencing the approach to achieving a high performance design. In addition, point-based systems reflect a weighting of the various environmental practices and impacts introducing subjectivity into the process. There is often no tracking of actual performance after a project is built. For sustainable design to evolve toward better practices and outcomes, this feedback loop must be more strongly established.

\subsection{Commercial Building Guidelines}

In commercial buildings, the most widely known and used national rating system is LEED from the US Green Building Council (USGBC). LEED is a pointbased system with credits in the following categories:

- Sustainable Sites

- Water Efficiency

- Energy and Atmosphere

- Materials and Resources

- Interior Environmental Quality

- Innovation and Design Process

Depending on the number of points, projects are Certified, Silver, Gold or Platinum. The LEED family of rating systems includes New Construction, Commercial Interiors, Core and Shell, Existing Buildings and some special versions for specific building types. The USGBC is participating in the development of ASHRAE 189P, Standard for High Performance Buildings.

Another national rating system, Green Globes, originated in Canada based on the BREEAM ${ }^{\mathrm{TM}}$ system from England and was introduced to the U.S. market by the Green Building Initiative. It is a point-based system with four levels of achievement from one to four globes. An existing building rating system called BOMA GoGreen in Canada is being introduced in the United States as the Green Globes Continuous Improvement Existing Building guidelines. The Green Globes rating system is going through the ANSI standards process. In addition to the national rating systems, a number of innovative sustainable guidelines reflecting regional and local issues have been developed (e.g. New York City High Performance Building Guidelines, Minnesota Sustainable Building Guidelines, and the Florida Commercial Building Guidelines).

\subsection{Residential Guidelines}

A separate set of voluntary environmental assessment 
and rating systems have been developed for the housing sector. At a national level, LEED for Homes has been developed by the USGBC as one of its family of rating systems. The National Association of Home Builders (NAHB) has developed the NAHB Green Building Guidelines. Both LEED for Homes and the NAHB Guidelines are point-based systems with multiple levels of achievement. The NAHB Guidelines are currently going through the ANSI standards process. There are numerous well-established local and regional green building programs such as the Austin Green Building Program, BuiltGreen Colorado, BuiltGreen Washington, and EarthCraft Homes in Atlanta.

In the affordable housing sector, the Green Communities Initiative was developed by Enterprise. Launched in the fall of 2004, the initiative is a five-year, $\$ 550$ million commitment to build more than 8,500 environmentally friendly affordable homes across the United States.

At the neighborhood scale, green development guidelines are emerging nationally (e.g. LEED ND) as well as regionally (e.g. Florida Green Development Guidelines).

\subsection{Summary of Current Trends}

- A diverse set guidelines and rating systems are continually evolving in response to the scale of development, building type and regional issues

- $\quad$ Guidelines are being adopted by states and cities as basis for codes, standards and incentives

- There is a movement away from simple pointbased checklists toward more requirements and a focus on performance outcomes such as carbon emissions and energy consumption

- Life cycle assessment of materials is beginning to be included in guidelines and ratings

- There is increasing interest in life cycle cost analysis

- There is increased focus on actual performance during operation and the need for a feedback loop and continuous improvement

\section{ROLE OF RESEARCH CENTERS}

There is a role for architectural research centers in accelerating the necessary transformation within the profession and building industry. In an academic setting, research centers have a number of potential benefits. They are responsive to real world problems and emerging opportunities, and have the ability to develop relationships and connect to funding sources. They also have the ability to assemble and manage interdisciplinary research teams within the University, and they can partner with the professional community and the building industry, which helps to frame research questions.

A center does not need to duplicate any existing organizations or components already playing an effective role in the building sector. Its mission can be strengthening connections between these groups, filling gaps, and creating synergies so the network functions more effectively.

One model for this type of organization is the Center for Sustainable Building Research (CSBR) at the University of Minnesota. The Center is in the process of creating an integrated sustainable building knowledge base for the Minnesota region. A key reason for this is the need to simplify information and use common metrics and methods across a wide range of projects and programs. The components of the CSBR Knowledge Base are:

1. Performance Indicators

2. Performance-Based Guidelines

3. Performance-Based Policy Framework

4. Tools and Information

5. Tracking Actual Performance

6. Regional Case Study Database

7. Design Assistance

8. Education and Training

CSBR is leading the establishment of Architecture 2030 standards in Minnesota, assisting local governments in writing green building policy, providing design assistance to local government, developing tools to assist design decision making, providing technical assistance to the affordable housing community in Minnesota, and establishing a regional case study database that includes actual performance information.

\subsection{Performance Indicators}

To address the problem of achieving clear outcomes, twelve measurable performance metrics have been identified. Wherever possible, benchmarks are set to provide a meaningful comparison of performance. As shown in Figure 1, these include:

\section{BUILDING METRICS \\ - Energy \\ - Water \\ - Waste water \\ - Solid waste \\ - Materials \\ - Indoor environmental quality}

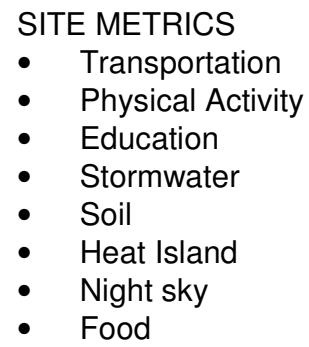

Some of these metrics are easily predicted during design (e.g. energy, water) and then can be measured during occupancy. Others are less predictable in design and can only measured during occupancy (e.g. IEQ, transportation use). In some cases, measurement methods are evolving (e.g. life cycle impacts of materials). 


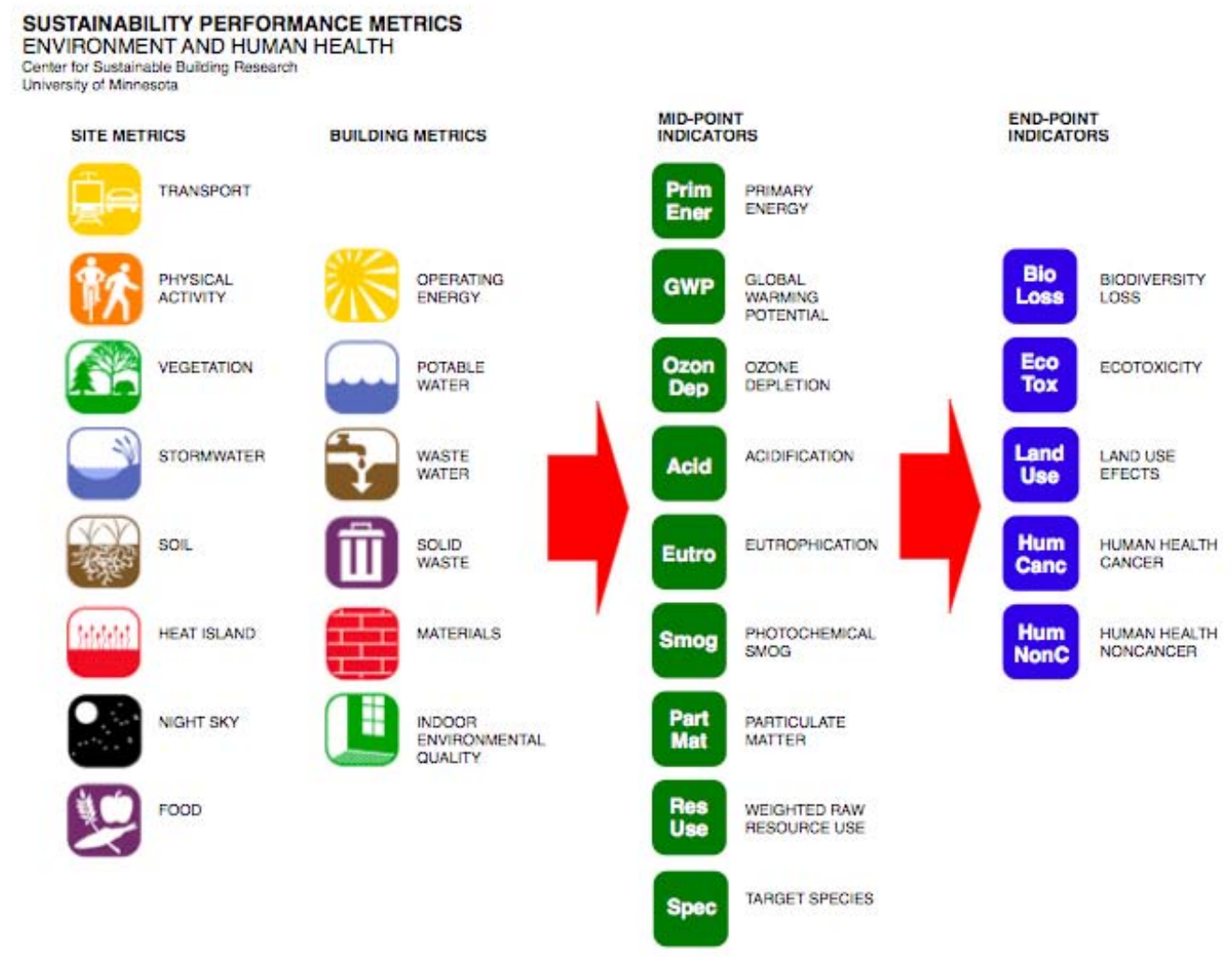

Figure 1: CSBR Sustainability Performance Metrics: Environment and Human Health Source: Center for Sustainable Building Research, University of Minnesota

The impacts of these metrics combined result in eight mid-point indicators shown in Figure 1 (ISO 2006). One of the most prominent of these is Global Warming Potential measured and $\mathrm{CO} 2$ equivalent. Ultimately, the mid-point indicators lead to end-point indicators concerning human health and environment.

\subsection{Performance-Based Guidelines}

CSBR is involved in two examples of performancebased guidelines and standards-the Minnesota Sustainable Building Guidelines (MSBG) and the Sustainable Buildings 2030 Project (SB 2030).

The Minnesota Sustainable Building Guidelines (MSBG) are an example of a regional system. The guidelines were mandated by state legislation for all projects with state funding. Consequently, they apply mostly to public buildings for state and local agencies. The need for regional systems is driven by the desire to integrate state programs and standards into the guidelines, the need to establish which guidelines are mandatory, and the need to set performance levels and add guidelines not covered by national guideline models. The Minnesota Sustainable Building Guidelines are not a point-based system and simply consist of the required or recommended guidelines in the following areas:

- Performance Management

- Site and Water

- Energy and Atmosphere

- Indoor Environmental Quality

- Materials and Waste

The benefit of having a mostly required set of guidelines is that all agencies and design teams know they must comply and application of a specific set of guidelines is ensured. Since there are no higher levels of achievement designated, this type of system does not result in the same level of recognition associated with LEED or Green Globes. The Minnesota Sustainable Building Guidelines are designed to emphasize actual performance outcomes as the basis for comparing buildings. As the user completes documentation, a scorecard or environmental balance sheet of key outcomes such as energy use and carbon emissions are determined. This lends itself to integration with performance-based initiatives such as Architecture 2030. The Minnesota guidelines also incorporate a regional version of the Athena EcoCalculator to determine actual environmental impacts of building assembly and material choices. 
CSBR now provides design assistance to project teams, tracks outcomes and generally serves as the feedback loop on the project.

The Sustainable Buildings 2030 program concept emerged from the recommendations of the Minnesota Climate Change Advisory Group and was passed by the Minnesota legislature in spring 2008. According to the legislation, the purpose is "to establish costeffective energy-efficiency performance standards for new and substantially reconstructed commercial, industrial and institutional buildings that can significantly reduce carbon dioxide emissions by lowering energy use." The performance standards are being designed to achieve the following reductions measured against energy consumption by an average building in each applicable building type in 2003: (1) 60 percent in 2010; (2) 70 percent in 2015; (3) 80 percent in 2020; and (4) 90 percent in 2025.

The legislation requires that the Center for Sustainable Building Research shall, in consultation with utilities, builders, developers, building operators, and experts in building design and technology, develop a Sustainable Building 2030 implementation plan that must address, at a minimum, the following issues:

1. training architects to incorporate the performance standards in building design;

2. incorporating the performance standards in utility conservation improvement programs; and

3. developing procedures for ongoing monitoring of energy use in buildings that have adopted the performance standards.

These standards will become the energy use requirements for state-bonded projects through the Minnesota Sustainable Building Guidelines. Utilities will be required to develop and implement conservation improvement programs that are expressly designed to achieve energy efficiency goals consistent with the Sustainable Building 2030 performance standards.

Program elements include:

- Set 2030 benchmarks for Minnesota buildings

- Assist in development of utility incentive programs

- Develop a case study database

- Track building performance in a database

- Develop knowledge base

- Assess needs and deliver training program for design professionals

- Assess needs and deliver training program for building operators

\subsection{Performance-Based Policy Framework}

To address the problem of multiple guidelines required by various funders and the concern over achieving certain outcomes, CSBR is assisting local governments in writing performance-based green building policies. Such a policy has been developed for the City of St. Paul for buildings that receive city resources.

The St. Paul policy has two requirements. First, the participant must choose one of the following rating systems and levels with which to comply:
COMMERCIAL PROJECTS:

- LEED New Construction (NC), Silver

- Green Globes, 2 globes

- B3 Compliant

- Saint Paul Port Authority Green Design Review

RESIDENTIAL PROJECTS

- LEED for Homes (H) or LEED NC (for large multifamily projects), Silver

- Minnesota Green Star, Silver

- Green Communities with Minnesota Overlay

The second requirement is that all projects must meet mandatory requirements within the chosen rating system. These requirements, known as the St. Paul Overlay, are:

- Predicted energy use must be at least $30 \%$ below current Minnesota Energy Code

- Predicted use of potable water in the building must be at least 30\% below EPA Policy Act of 1990.

- Predicted water use for landscaping must be at least $50 \%$ less than a traditionally irrigated site using typical water consumption for underground irrigation systems standards

- Actual solid waste of construction materials must be at least $75 \%$ recycled or otherwise diverted from landfills.

- Indoor Environmental Quality must include the following strategies: increased ventilation, construction IAQ management plan, low-emitting materials, and thermal comfort

- Predicted on site stormwater management of volume and quality must be achieved for 1 " rain events or less.

- Predicted greenhouse gas emissions must equal or be less than MN 2030 benchmark calculated on energy use

- Actual annual energy consumption data for the project must be entered into the State's B3 Benchmarking Database by the building owner or utility.

Each project's compliance with the Green Building Policy must be verified, in accordance with the verification method specified by the selected rating system.

\subsection{Tools and Information}

CSBR is involved in the development of tools and information to aid in decision making and compliance with performance requirements during design. Four examples are discussed below.

Determining greenhouse gas emissions is required more frequently on building projects. There are many calculators available that produce different results based on different assumptions. CSBR has developed a transparent Greenhouse Gas (GHG) Calculator for Minnesota building projects to provide a comprehensive and consistent approach. The 
calculator includes greenhouse gas impacts from several sources such as operating energy, water treatment and pumping, waste water treatment, solid waste, embodied effects of materials, transportation, vegetation, and soil disruption (see Figure 1).

Life cycle assessment represents an important advance from prescriptive practices to performancebased outcomes. CSBR has worked with the Athena Institute to develop a life cycle assessment tool called the Athena EcoCalculator that determines environmental impacts of building assemblies and materials (Athena 2007). The Athena EcoCalculator is now being integrated into both the LEED and Green Globes rating systems. It is also part of the Minnesota Sustainable Building Guidelines and the CSBR Greenhouse Gas Calculator. Life cycle assessment analysis can also be used to determine the avoided environmental impacts resulting from reusing existing buildings.

Another example is the Efficient Windows Collaborative program sponsored by the US Department of Energy. With increasing concerns over rising energy prices and the effects of greenhouse gas emissions on climate change, high performance windows and facades will play a key role in the transformation to more energyefficient, sustainably-designed buildings. For over twenty years, the U.S. Department of Energy has supported a vertically integrated program to develop and advance the adoption of high performance windows and facades in both residential and commercial buildings. This work has been centered at Lawrence Berkeley National Laboratory in collaboration with CSBR and the Alliance to Save Energy, as well as window industry partners. The unique aspect of the program is the connection between basic and applied research, development of an extensive suite of tools to assess performance and assist decision making, and market transformation strategies that reduce barriers to the adoption of high performance windows and façades.

A final example is the Knowledge Base and Technical Assistance Program for Affordable Housing funded by McKnight Foundation in which the Center for Sustainable Building Research plays multiple roles in transforming the affordable housing sector in Minnesota toward sustainable design. The broad goal of the project is to assist in the transformation of affordable housing to be more energy efficient, healthy, and durable with reduced environmental impacts. To accomplish this, a knowledge base and technical assistance program are being developed for affordable housing in the region. The primary focus of this work is to develop the necessary tools and methods to evaluate real performance outcomes addressing the cost, energy efficiency, health, durability, and environmental impacts of the housing. These methods are being applied to selected case studies. The results will be included in a comprehensive knowledge base that serves key decision makers involved in the delivery of both single- and multi-family affordable housing.

\subsection{Tracking Actual Performance}

Tracking actual performance during building operation is critical to provide a feedback loop resulting in continuous improvement. The MSBG project is part of a larger project that includes tracking energy use in several thousand public buildings in Minnesota. Developed by The Weidt Group, this project is called the B3 Benchmarking Tool. This database forms the bases for future tracking of buildings that are part of the SB 2030 program. More in depth performance tracking occurs through post occupancy evaluations of exemplary sustainable building projects in the region.

\subsection{Regional Case Study Database}

One problem that occurs with the broad range of research activities and programs in the green building world is that information is scattered and often not collected in a consistent format. It becomes difficult to find relevant examples in a given region that clearly show performance and cost. For this reason, CSBR is developing a regional case study database across multiple research projects. This also addresses the problem that examples from other regions are not considered applicable in a local situation.

\subsection{Design Assistance}

CSBR continues to provide design assistance as part of many research programs such as the Minnesota Sustainable Building Guidelines. Recently, the Center has worked with graduate students to provide conceptual design services to communities through the Regional Sustainable Development Partnership. Design assistance is also provided to local governments and non-profit organizations.

\subsection{Education and Training}

A research center can also fill major gaps in providing in depth professional education as well as be a catalyst for demonstration projects and public education. CSBR provides faculty for the sustainable design track in the MS degree in the School of Architecture as well numerous continuing education classes. Projects such as Sustainable Buildings 2030 will lead to specific training programs for design professionals and building operators.

\section{CONCLUSION}

Architectural research centers at Universities have an important role to play in the major transformation of building design, construction and operation in response to climate change and other environmental degradation. Using examples from the Center for Sustainable Building Research at the University of Minnesota, there are several key concepts in developing and delivering effective knowledge to the profession.

1. Work at a regional scale. Research and case studies from other regions are often not viewed as applicable because of climatic and regulatory differences. Within a region, it is possible to develop the social networks and information flows needed to 
gather information, discover problems and find solutions.

2. Emphasize performance outcomes. Green building rating systems are useful in increasing awareness and providing an accessible process for delivering a building, but they are a surrogate for real performance. Moving to actual metrics and performance indicators is essential during design and later assessment of results.

3. Create feedback loops. It is critical that the actual performance of buildings is tracked and compared to relevant benchmarks. This information must then be communicated in an easily accessible way to building designers, owners, and operators so that continuous feedback and improvement can take place. Effective design of the knowledge base is important to meet this goal.

4. Seek simple tools and solutions. It is important not to overwhelm busy design professionals with detailed research studies and complex software programs. Research centers should design tools and package information so that decisions can be made quickly if necessary but more depth can be explored if desired. As much as possible tools should aid designers in making decisions based on performance outcomes.

\section{ACKNOWLEDGMENTS}

All of the projects mentioned in the paper and their underlying concepts were developed as collaborative efforts with CSBR staff and others. CSBR staff include Richard Strong, Jonee Brigham, William Weber, Kerry Haglund, Virajita Singh and Dan Handeen. Outside collaborators on key projects such as the Minnesota Sustainable Building Guidelines and SB 2030 include The Weidt Group, LHB Inc., Center for Energy and the Environment, and Herzog Wheeler and Associates. I am particularly grateful to Wayne Trusty of the Athena Institute for his input on many of the projects and concepts described here. Finally, I would like to thank the many sponsors of projects mentioned in the paper. These include the Minnesota Departments of Administration and Commerce, the Minnesota Pollution Control Agency, the McKnight Foundation, the US Department of Energy, and the Athena Institute.

\section{REFERENCES}

Architecture 2030. May 12 2007. http://www. architecture2030.org

Athena Ecocalculator for Assemblies. Athena Institute International. May 25 2007. http://www.athenaSMl.ca/

California Department of Transportation (CALTRANS), 2002. Statewide Transit-Oriented Development Study: Factors for Success in California, May p. 5.

Climate Change 2007. Intergovernmental Panel on Climate Change (IPCC). 2007. November 30 2007.http://www.ipcc.ch/
Cole, Raymond J. 2006. Editorial: Building Environmental Assessment: Changing the Culture of Practice. Building Research and Information, JulyAugust Volume 34, Number 4, 303-307.

Cole, Raymond J. 2006. Shared Markets: Coexisting Building Environmental Assessment Methods. Building Research and Information, July-August Volume 34, Number 4, 357-371.

Ecosystems and Human Well-Being: Synthesis. Millennium Ecosystem Assessment. Washington DC: Island Press, 2005. <http://www.millennium assessment.org/en/ Synthesis.aspx>

Florida Green Commercial Building Standard. Florida Green Building Coalition <http://floridagreenbuilding. org/standard/com/ default.htm>

Florida Green Development Standard. Florida Green Building Coalition. <http://floridagreenbuilding.org/ standard/devs/ Default.htm>

Green Globes Rating System. Green Building Initiative. May 12 2007. <http://www.thegbi.org/greenglobes/>

International Standards Organization (ISO). 2006. ISO 21930, Environmental Declarations of Building Products. Draft-September.

Minnesota Sustainable Building Guidelines. Center for Sustainable Building Research. University of Minnesota 12 May 2007. <http://www.msbg.umn. edu>

National Association of Home Builders. 2007. NAHB Green Building Guidelines. http://www.nahb.org/ publication details.aspx?publicationID=1994\&sectionID $\underline{=155}$

New York City Department of Design and Construction. 1999. High Performance Building Guidelines. May 12 2007. <http://www.ci.nyc.ny.us/html/ddc/html/ddcgreen/ highperf.html>

New York City Dept. of Design and Construction. 2005. High Performance Infrastructure Guidelines. <http:// www.ci.nyc.ny.us/html/ddc/html/ddcgreen/ documents/hpig.pdf>

Roodman, D.M., and N. Lenssen. 1995. A building revolution: how ecology and health concerns are transforming construction. Worldwatch Paper 124. Washington, D.C.: Worldwatch Institute.

U.S. Green Building Council. 2007. LEED Rating System for New Construction. 12 May. http://www. usgbc.org/

U.S. Green Building Council. 2007. LEED Rating System for Neighborhoods. 12 May. http://www. usgbc.org/ 